\title{
Recurrent hyperparathyroidism due to parathyroid carcinoma
}

\author{
H. A. ELLIS, M. FLOYD, AND F. K. HERBERT ${ }^{1}$
}

From the Departments of Pathology. Medicine, and Clinical Biochemistry, The Royal Victoria Infirmary, Newcastle upon Tyne.

SYNOPSIS The case is described of a woman who died with a functioning parathyroid carcinoma 19 ? years after removal of two parathyroid tumours, considered at the time to be benign. Following $₫$ operation hyperparathyroidism subsided, with a short period of hypocalcaemia, and severe osteitis ir fibrosa cystica healed. Five years before death progressive renal failure developed with normal and $\mathscr{\odot}$ later raised serum calcium levels. At necropsy a parathyroid carcinoma infiltrated the thyroid at the $ᄋ$ site of the previous operation and there was a solitary hepatic metastasis. A remaining parathyroid gland was nodularly hyperplastic and the bones showed evidence of active osteitis fibrosa. The $\bigcirc$ relationship between parathyroid hyperplasia and neoplasia is discussed. Acceptable cases of $\stackrel{\odot}{\circ}$ parathyroid carcinoma are rare, but carcinoma is an important cause of recurrent hyperparathyroid- $\underset{\mathbb{D}}{\mathscr{D}}$ ism even months or years after removal of an 'adenoma'.

Primary hyperparathyroidism is uncommon although our ideas concerning its precise incidence are being modified with the introduction of serum autoanalysers. Thus Haff, Black, and Ballinger (1970) have recently reported the recognition of 47 patients with hyperparathyroidism in a 30-month period after routine calcium estimations on all patients admitted to one hospital, whereas only 39 cases had been recognized in the same hospital in the previous 10 years. Hypercalcaemia due to hyperparathyroidism was found in one of every 2,000 patients examined.

Primary hyperparathyroidism is usually due to parathyroid adenoma, less commonly to primary water-clear cell or chief cell hyperplasia (Castleman, 1952; Cope, Keynes, Roth, and Castleman, 1958), and rarely to carcinoma (in about 0.5 to $1.0 \%$ of cases; Woolner, Keating, and Black, 1952; Beahrs, Angelos, and Woolner 1963). We have not made an exhaustive survey of the literature but the number of acceptable recorded cases of parathyroid carcinoma is still limited to around 50. Useful reports and reviews are those by Gentile, Skinner, and Ashburn (1941), Meyer and Ragins (1943), Norris (1948), de Wesselow and de Wardener (1949), Young and Emerson (1949), Black and Ackerman (1950), King and Wood (1950), Stephenson (1950), Black and

${ }^{1}$ Retired in 1965.

Roceived for publication 30 December 1970.
Haynes (1951), Ellis and Barr (1951), Woolner et al (1952), Wray (1953), Black (1954), Fredell, McIver, and Ferrebee (1957), Cook (1958), Tange (1958), $\stackrel{\circ}{\triangleright}$ Rapoport, Sepp, and Brown (1960), Lazar, Landau, and Kappas (1961), Pollack, Goldin, and Cohen (1961), Caley, Jones, and Collins (1962), Cope (1966), Goepfert, Smart, and Rochlin (1966), Mansour and Letton (1967), Newton and Sumich (1968), Kelly (1969), Straus and Paloyan (1969), and Holmes, $\frac{8}{8}$ Morton, and Ketcham (1969). The association of 0 parathyroid hyperplasia with neoplasia has been 3 emphasized by Golden, Canary, and Kerwin (1965) and more recently by Kramer (1970).

The present case of hyperparathyroidism has a응 number of unusual features, including the association of parathyroid hyperplasia, multiple adenomas, ando carcinoma, the last named causing recurrent hyperparathyroidism 19 years after removal of two. apparently benign adenomas.

\section{Case Report}

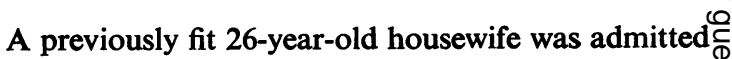
to the Royal Victoria Infirmary in November 1945 with persistent vomiting, polyuria, polydipsia, and 0 weight loss. There were no abnormal physical signs. Investigation revealed persistent moderately heavy $\overrightarrow{\mathbb{Q}}$ proteinuria and cylinduria and the blood urea was $\overrightarrow{\mathrm{D}}$ $88 \mathrm{mg} / 100 \mathrm{ml}$. A presumptive diagnosis of "chronic 596 
nephritis' was made and the patient discharged. She returned in June 1948 with the same complaints. On examination she appeared poorly and emaciated. She had a fractured left femur and a small nodule was palpable in the right upper thyroid region. Investigations indicated a raised serum calcium level $(19.3 \mathrm{mg} / 100 \mathrm{ml})$ shown to be due to a rise in the diffusible fraction, normal plasma phosphorus $(3.4 \mathrm{mg} / 100 \mathrm{ml})$, raised serum alkaline phosphatase (31.5 Jenner and Kay units), haemoglobin $13.3 \mathrm{~g} \%$, and raised blood urea $(93 \mathrm{mg} / 100 \mathrm{ml})$. Radiological examination showed generalized osteitis fibrosa and bilateral nephrocalcinosis. Apart from the fractured shaft the superior metaphysis of the left femur was replaced by a large multilocular cyst (Fig. 1) attributable to osteitis fibrosa cystica. Exploration of the neck by Mr T. A. Hindmarsh on 15 July 1948 revealed right upper and left lower parathyroid adenomas which were removed.

The specimen from the right upper pole of the thyroid was described as an encapsulated tumour measuring $2.5 \mathrm{~cm}$ in maximum diameter and weighing $5 \mathrm{~g}$. On bisection it was mainly solid with areas of cystic degeneration and haemorrhage and subcapsular foci of calcification. That from the left

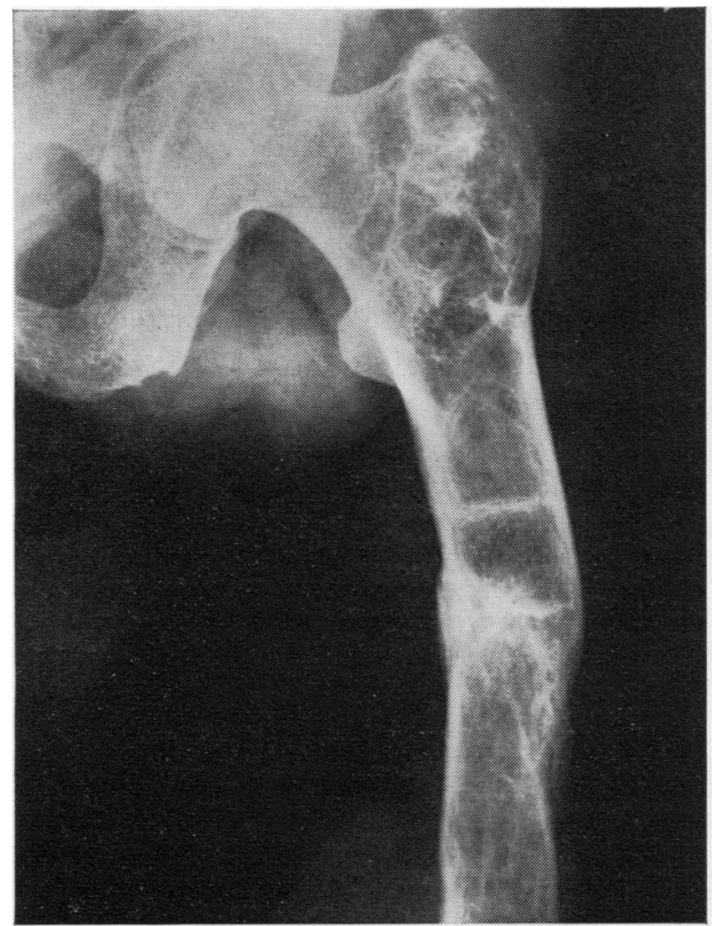

Fig. 1 Radiograph of left femur in 1948, showing osteitis fibrosa cyotica and fracture. lower pole of thyroid was described as a partly fragmented tumour of similar appearance. Histologically both tumours were thickly encapsulated and comprised polygonal cells with areas of degeneration, haemorrhage, deposition of cholesterol, and focal calcification. They were considered to be benign parathyroid adenomas.

Postoperatively the patient had symptomatic hypocalcaemia for at least six months before the serum calcium level returned to normal. During this time the osteitis fibrosa and the femoral fracture healed. The blood urea returned to normal and was $44 \mathrm{mg} / 100 \mathrm{ml}$ in September 1948. In 1949 the patient was able to carry through a normal pregnancy and was delivered of a healthy son by Caesarean section in January 1950 . By mid 1950 when she was still enjoying good health: the serum calcium was variously $10.5,10 \cdot 6$, and $10.8 \mathrm{mg} / 100 \mathrm{ml}$ with corresponding phosphorus values of $1 \cdot 8,2 \cdot 3$, and $2.3 \mathrm{mg} / 100 \mathrm{ml}$. The blood urea on six occasions between 1950 and 1954 was recorded at the upper limit of normal (from 40 to $48 \mathrm{mg} / 100 \mathrm{ml}$ ). Figure 2, which summarizes the biochemical changes, shows a tendency to high serum calcium and low plasma phosphorus levels throughout the 1950s. The patient was asymptomatic, and apart from an uneventful appendicectomy in 1958, remained relatively well until December 1961 when admitted with abdominal pains and vomiting. This was attributed to the digitalis recently started for mild hypertensive heart failure. In March 1962 the patient developed severe paroxysmal nocturnal dyspnoea and was found to have a blood pressure of $310 / 170 \mathrm{~mm} \mathrm{Hg}$. She now had symptomatic renal failure with anorexia and a blood urea of $190 \mathrm{mg} /$ $100 \mathrm{ml}$. The clinical features of chronic renal failure slowly advanced over the remaining five years. In this period the patient developed band keratopathy and arterial calcification. Radiological investigation showed thinning of cortical bone of the phalanges but no subperiosteal erosions and nephrocalcinosis persisted. During this azotaemic phase, which lasted from 1962 until her death in 1967, she consistently had serum calcium values in excess of $8 \mathrm{mg} / 100 \mathrm{ml}$. Two values of 10.2 and 10.6 were found in 1966 when she had a plasma urea of 200 $\mathrm{mg} / 100 \mathrm{ml}$. Serum phosphorus levels as shown in Fig. 2 were consistently between 2 and $5 \mathrm{mg} / 100 \mathrm{ml}$ during this period of increasing renal failure. Death from chronic renal failure occurred in February 1967 with terminal hypercalcaemia.

\section{Postmortem Examination}

A limited examination was possible about one year after death since the body had been preserved and 


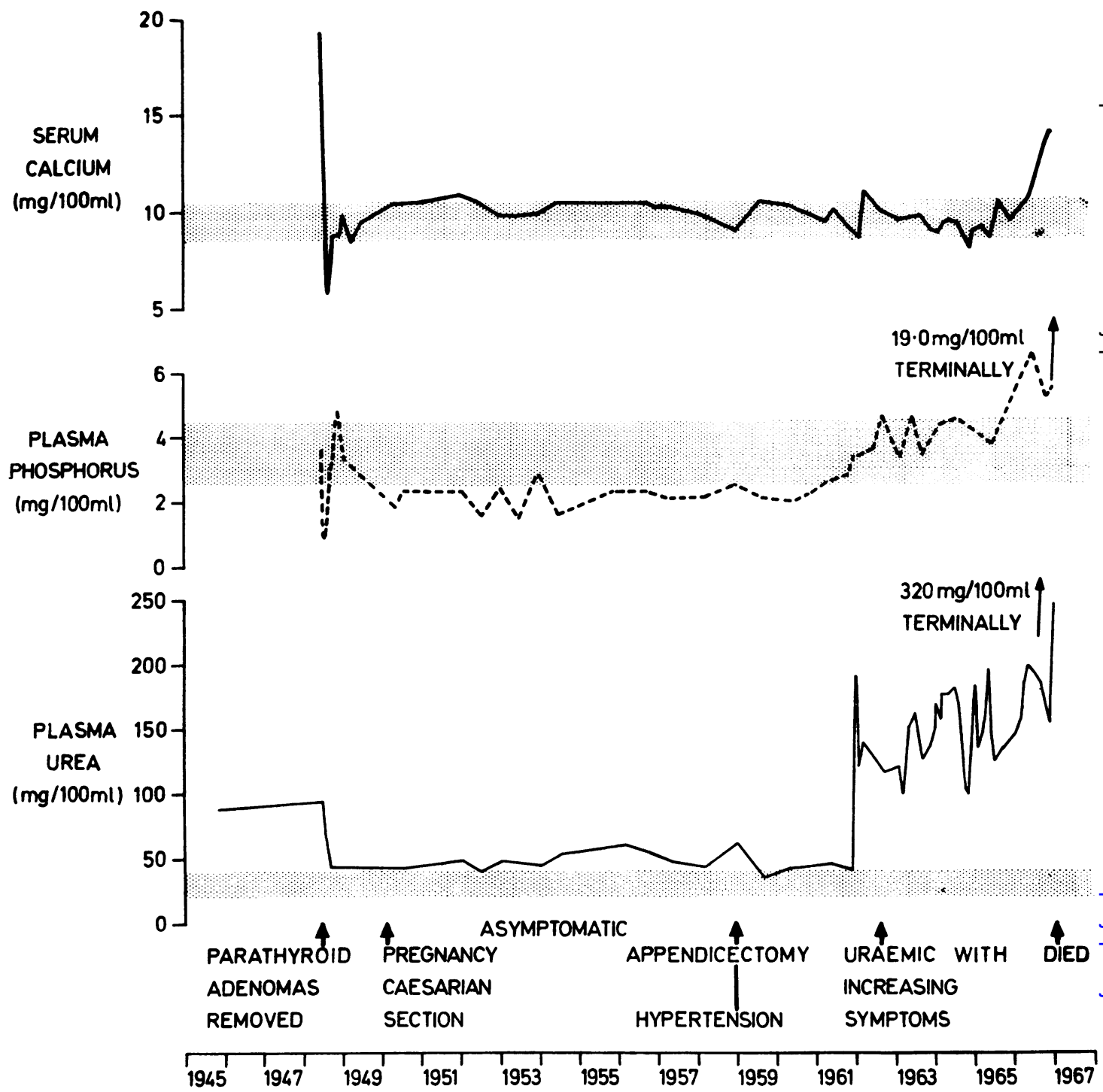

Fig. 2 Fluctuations in serum calcium, plasma phosphorus, and urea. Note the initial fall in serum calcium following removal of adenomas in 1948, the transient period of hypocalcaemia and terminal hypercalcaemia. Progressive uraemia occurred in the last five years. Stippled zones represent normal ranges for serum calcium, plasma, phosphorus, and urea.

partly dissected in the Anatomy Department of the University of Newcastle upon Tyne. Only the main relevant findings will be described.

\section{THYROID AND PARATHYROID GLANDS}

The thyroid had already been removed from the neck. It was small, pale brown, and firm, the right and left lobes measuring $5 \times 3 \times 2 \mathrm{~cm}$ and
$3 \times 1.5 \times 1.5 \mathrm{~cm}$, respectively. The upper twothirds of the right lobe showed extensive infiltration of its capsule and substance by firm white tumour $\stackrel{?}{?}$ forming an irregular mass measuring approximately 0 $2 \times 2 \times 1 \mathrm{~cm}$. Peripherally this formed rounded ${ }^{\circ}$ nodules where tumour was infiltrating vessels. The $\mathbb{\otimes}$ only remaining parathyroid gland identified was $\overrightarrow{\mathbb{D}}$ attached to the lower pole of the left thyroid lobe, 


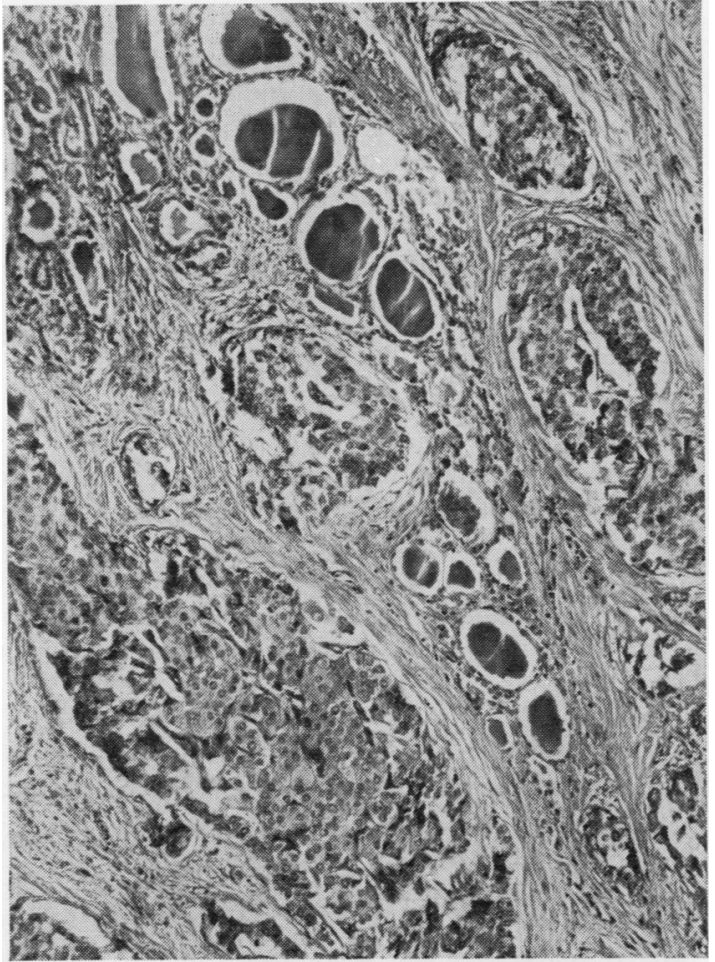

was enlarged to $1.5 \times 1 \times 1 \mathrm{~cm}$ and included a haemorrhagic area $0.3 \mathrm{~cm}$ in diameter. No lymph nodes were found in the neck of the cadaver.

Histological examination showed parathyroid carcinoma infiltrating the right lobe of the thyroid (Fig. 3) apparently at the site of the previous operation where there was also fibrosis, deposition of haemosiderin, and foci of foreign body giant cells in relation to old suture material. The tumour, which was also infiltrating and largely replacing nerve fibres (Fig. 4) and involving blood vessels, comprised rounded collections of polygonal cells with prominent cell borders, faintly granular and eosinophilic cytoplasm, and regular rounded or ovoid nuclei. There were moderate numbers of mitotic figures (Fig. 5) and some water clear cells. In places there was central necrosis of lobules of tumour with patchy granular calcification.

The remaining left lower parathyroid gland was histologically abnormal (Fig. 6). Part of the gland retained a lobular pattern but appeared hyperplastic with loss of fat cells throughout. This part comprised transitional and chief cells with scattered oxyphils sometimes in aggregates generally up to $0 \cdot 1 \mathrm{~cm}$ in diameter but with one larger nodule of oxyphils in a trabecular arrangement measuring $0.3 \mathrm{~cm}$ in maximum diameter. Much of the gland was taken up by

FIG. 3

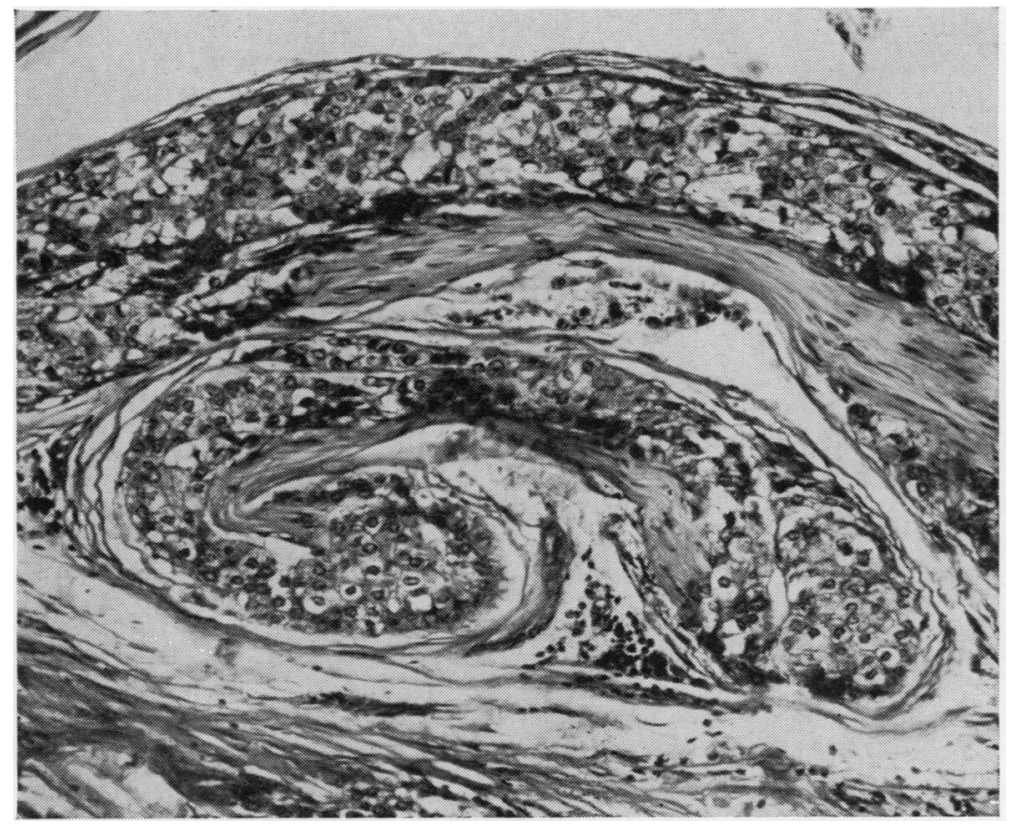

Fig. 3 Parathyroid carcinoma infiltrating right lobe of thyroid at necropsy. Haematoxylin and eosin $\times 140$.

Fig. 4 Parathyroid carcinoma locally infiltrating and replacing nerves. Haematoxylin and eosin $\times 200$.

FIG. 4 


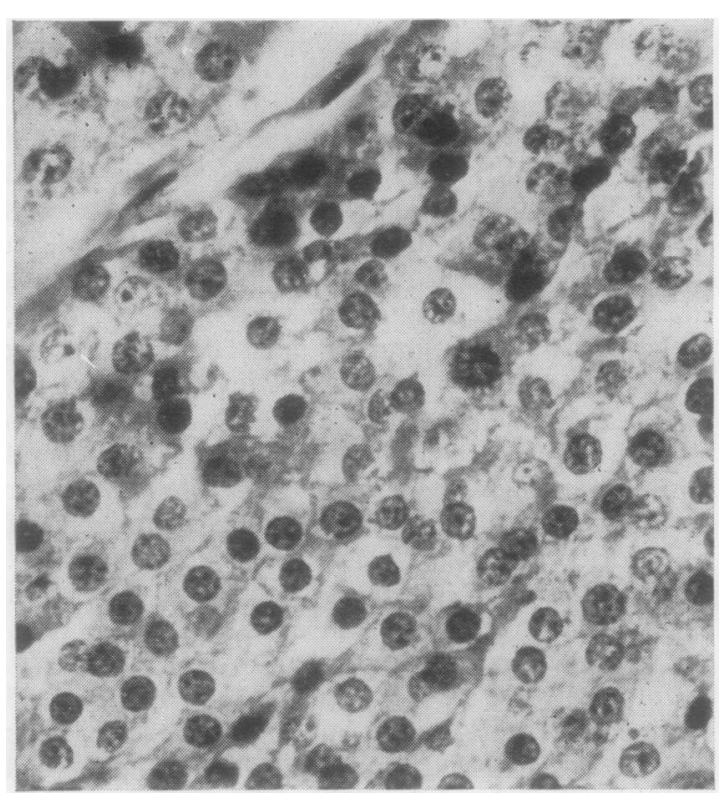

Fig. 5 Parathyroid carcinoma showing uniform nuclei and a mitosis (centre). Haematoxylin and eosin $\times 525$.

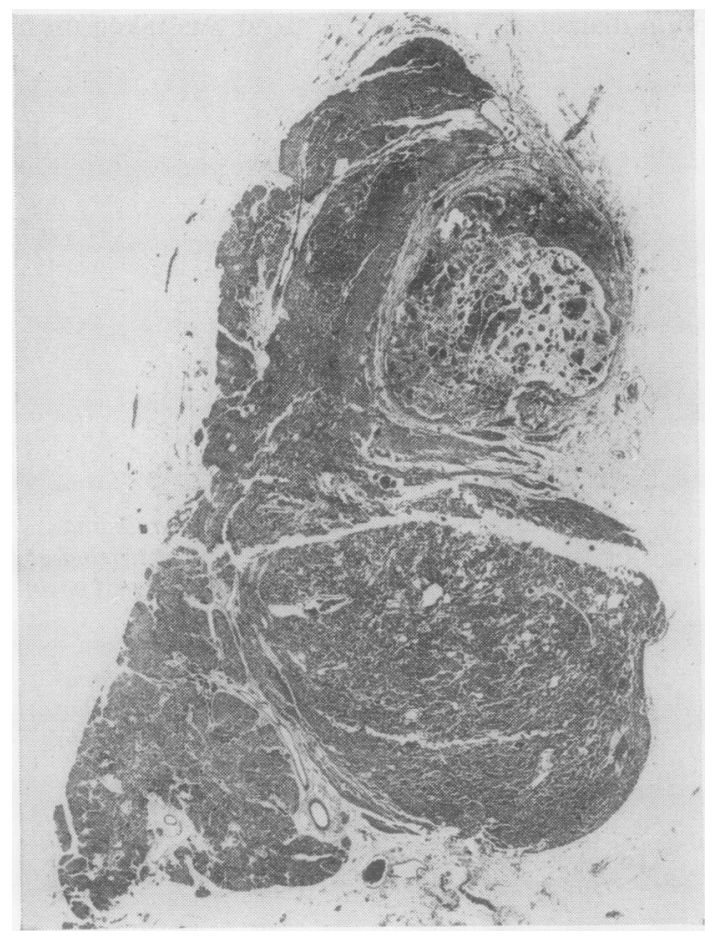

Fig. 6 Nodular hyperplasia of parathyroid gland from lower pole of left lobe of thyroid at necropsy. Haematoxylin and eosin $\times 8$.
H. A. Ellis, M. Floyd, and F. K. Herbert $\frac{\varrho}{\bar{\Xi}}$ areas of nodular or 'adenomatous' hyperplasia. The $\frac{\stackrel{0}{\vec{\sigma}}}{0}$ largest affected area measured $0.5 \mathrm{~cm}$ in diameter and formed a non-encapsulated nodule of columnar chief $\underset{\overrightarrow{\mathrm{s}}}{\overrightarrow{\mathrm{s}}}$ cells arranged in a trabecular pattern with some $-\frac{7}{-}$ pseudo-alveoli and occasional true columnar-celled $\frac{5}{2}$ alveoli. The haemorrhagic nodule was a small, $\overline{\bar{\omega}}$ fibrous-walled cyst with scattered water-clear cells $\widehat{\Phi}$ in the wall and recent intraluminal haemorrhage. Mitoses were not observed and the nuclei throughout ${ }^{\circ}$ the gland were fairly uniform in size apart from the $\overrightarrow{0}$ presence of very occasional enlarged nuclei.

LIVER

There was a single rounded mass of metastatic tumour in the liver measuring approximately $\rightarrow$ $2 \times 1.5 \times 1.5 \mathrm{~cm}$ with extensive central necrosis. $v$ Histologically the metastasis was similar in appearance to the tumour infiltrating the thyroid region. 0 Random sections from other parts of the liver? failed to reveal microscopic foci of carcinoma.

BONE

Decalcified and undecalcified sections were obtained $\stackrel{\mathbb{D}}{2}$

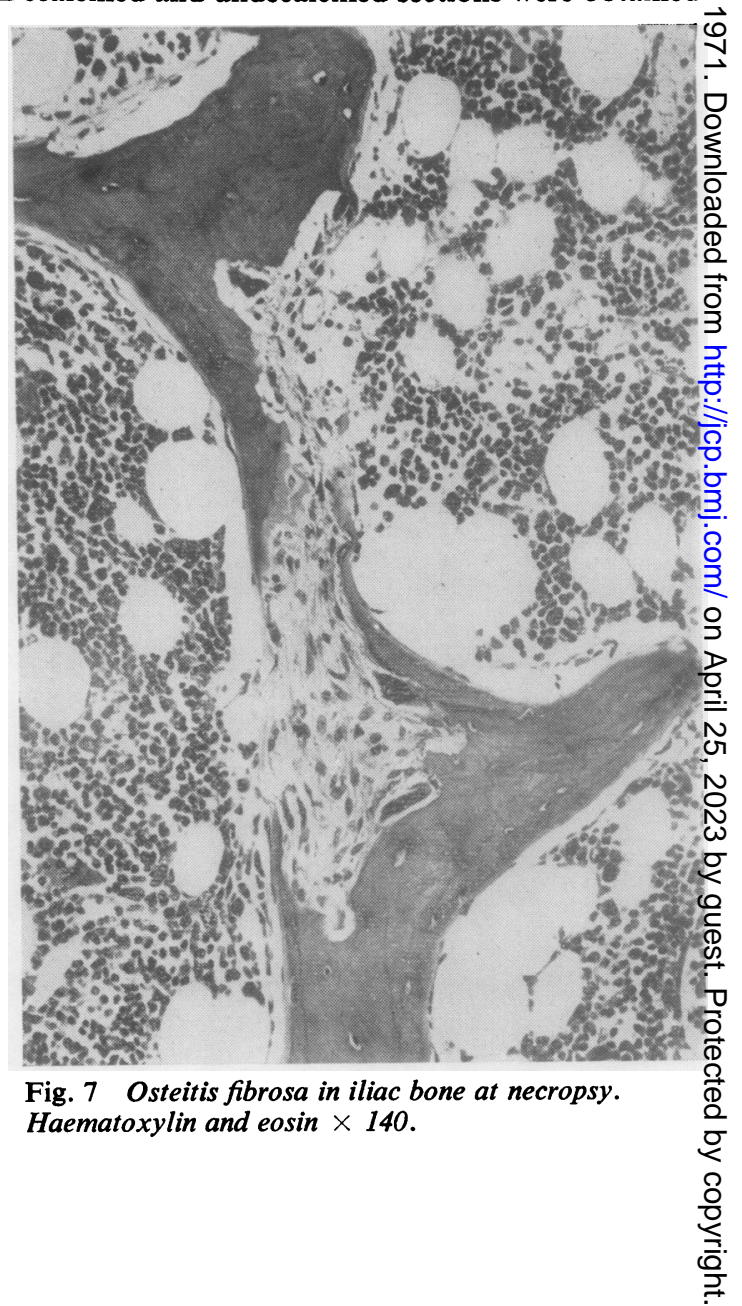


from an iliac crest and rib. There was no evidence of metastatic carcinoma. There were moderately severe changes of osteitis fibrosa due to hyperparathyroidism with focal osteoclastic resorption of bone, marrow fibrosis, and formation of pathological (woven) bone (Fig. 7). Undecalcified sections revealed osteoid seams at the sites of new bone formation but these were nowhere unduly wide and there was no evidence of osteomalacia.

\section{KIDNEYS}

These were uniformly and symmetrically diminished in size, the right and left kidneys measuring $7.5 \times$ $5 \times 2.5 \mathrm{~cm}$ and $8 \times 4.5 \times 2.5 \mathrm{~cm}$, respectively. The pelves were not dilated and the cortex was approximately $0.5 \mathrm{~cm}$ in width.

Histologically, there was atrophy of the parenchymatous elements with hyalinization and fibrosis of most glomeruli. There was hyalinization of arterioles and intimal fibrous thickening of arteries, widespread focal microscopic nephrocalcinosis, and marked diffuse interstitial fibrosis. There was no evidence of a primary renal disease and the appearances were consistent with those described in primary hyperparathyroidism (Heptinstall, 1966).

\section{OTHER ORGANS}

Adenomas were not found in the adrenal glands or in the pancreas. The pituitary was not available. There was no gross or microscopic evidence of calcinosis or metastatic tumour in the lungs. The arteries in a number of viscera showed calcification of their walls especially in the elastic lamellae. There was no evidence of pancreatitis which may accompany hyperparathyroidism (Scharf, Better, Gellei, Hemli, Peled, and Brandstaetter, 1969).

\section{Review of Parathyroid Tumours Removed 19 years before Death}

In the light of this patient's subsequent history the histology of the original parathyroid tumours has been reviewed (Figs. 8, 9, and 10).

It is doubtful if any pathological interpretation could have been made at the time other than that both tumours were parathyroid adenomas. Both showed enlarged nuclei with some variation in nuclear size and chromatism but this is a well recognized feature of benign adenomas. A careful search for mitoses revealed only one to two per section. Castleman (1952) is of the opinion that mitoses are not found in benign adenomas but this is probably too dogmatic a view (Caley et al, 1962). Another feature is the tendency towards an elongation and 'spindling' of parathyroid tumour cells arranged prominently in palisades around blood vessels in parts

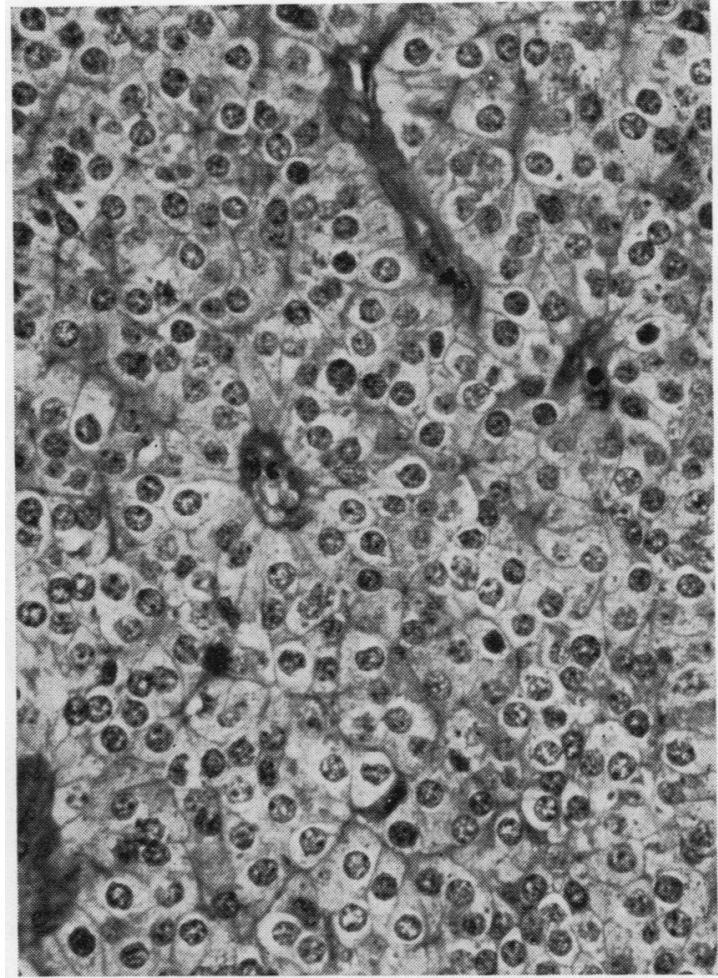

Fig. 8 Parathyroid tumour removed in 1948 showing regular box-like cellular structure. Haematoxylin and eosin $\times 350$.

of both the tumours (Fig. 9). A number of writers have observed this appearance in apparently benign adenomas which have recurred and Castleman regards this as a sign of potential malignancy. Unfortunately the left-sided adenoma was fragmented but there appear to be fibrous trabeculae extending from the main capsule into the substance of the tumour. Again this has been repeatedly reported in the literature in 'adenomas' which have later recurred locally or metastasized. The only additional feature of note was the presence of a demilune of compressed but apparently hyperplastic parathyroid tissue in the outer part of the capsule of the right adenoma (Fig. 10). It was here devoid of fat cells and presented a compact cellular structure, with some variation in nuclear size but no mitoses.

\section{Discussion}

The present patient had right and left-sided functioning parathyroid tumours which at the time were considered to be benign. Nineteen years later she died with evidence of recurrent hyperparathyroidism 
Fig. 9

Fig. 10

Fig. 9 Same as Fig. 8 showing palisading of elongated cells in relation to blood vessels. Haematoxylin and eosin $\times 350$

Fig. 10 Parathyroid tumour removed from right side in 1948 showing fibrous capsule (centre) with hyperplastic parathyroid tissue externally (right). Haematoxylin and eosin $\times 90$.

and limited necropsy showed a locally infiltrating parathyroid carcinoma at the site of previous removal of the tumour on the right side with a solitary metastasis to the liver, together with nodular hyperplasia of the remaining left inferior parathyroid gland, osteitis fibrosa, and some nephrocalcinosis.

It is generally agreed that a tumour can only be considered a parathyroid carcinoma when it is associated with appropriate endocrine effects (to distinguish it from thyroid carcinoma which may simulate it histologically) and shows definite evidence of malignancy such as infiltration of the thyroid and other tissues locally, metastasis to regional lymph nodes, or more widespread visceral metastasis. The tumour in the present case fulfils these criteria since there was a recurrence of hypercalcaemia, changes of osteitis fibrosa in the bones, local infiltration of nerves, vessels, and thyroid, and a metastasis in the liver. Some writers (Black and Ackerman, 1950) are reluctant to accept local infiltration as definite evidence of malignancy in cases of recurrent parathyroid adenoma when no infiltration is found at the initial operation, claiming that such growth might be from operative implantation of cells. Our experience with the present case is more in keeping with the view of Castleman (1952) $\overline{\bar{o}}$ that local recurrence of tumour in the majority of instances is proof that the original lesion was a carcinoma. Late recurrence of a truly benign parathyroid adenoma appears to be exceptional. $\frac{\overline{0}}{8}$ Castleman (1952) refers to six cases of adenoma $\dot{0}$ where subtotal resections were performed deliberately in an attempt to prevent postoperative tetany. $\delta$ Three had no further evidence of hyperplasia and in the other three there was little, if any, further growth $\circ$ of the residual tissue when removed five months, seven years, and 15 years later, respectively.

The literature reveals a similar history in many instances. In some cases parathyroid carcinoma has .7 been diagnosed at the initial operation, but a not $N$ uncommon story is of primary hyperparathyroidism $N$ relieved by resection of an apparently benign 0 adenoma followed months or even years later by $a<$ recurrence of hyperparathyroidism with carcino- $\frac{-}{D}$ matous infiltration in the neck or visceral metastases, $\stackrel{\infty}{\rightarrow}$ usually in the lungs. Other sites for metastatic ${ }_{0}$ tumour include the liver and kidney and rarely bone $\bar{O}$ (Pollack et al, 1961). Hepatic metastasis which oc- $\overparen{\mathbb{Q}}$ curred in the present case has also been reported in $\overrightarrow{\mathbb{D}}$ individual cases by Ellis and Barr (1951), Castleman 
(1952), Lazar et al (1961), and Straus and Paloyan (1969). Recurrence of hyperparathyroidism due to carcinoma may be very much delayed. Thus in the case described by Caley et al (1962) there was an interval of seven years between the removal of an 'adenoma' and death from recurrent parathyroid carcinoma. In the present case the corresponding period was no less than 19 years. This pattern of recurrent hyperparathyroidism seems to be characteristic and the late recurrence of symptoms and signs of hyperparathyroidism in a patient following removal of an apparently benign adenoma should suggest the possibility of carcinoma. Where the initial hyperparathyroidism is unrelieved by resection of an adenoma the situation is different, and then a further adenoma which has been overlooked or adenomatous hyperplasia involving multiple glands are possibilities.

There are three possible relationships between the changes of parathyroid hyperplasia and neoplasia observed in the present case: (1) an initial primary chief cell nodular (adenomatous) hyperplasia of parathyroid glands which had progressed to the stage of 'adenoma' formation in two glands at the time of operation and later to frank carcinoma with adenomatous hyperplasia still recognizable in the remaining gland found at necropsy; (2) an initial secondary hyperplasia of parathyroid glands associated with longstanding chronic renal disease with development of 'adenomas' (St Goar's so-called tertiary hyperparathyroidism; Davies, Dent, and Watson, 1968; Smith, 1970) and later carcinoma; and (3) an initial development of true adenomas in two parathyroid glands at least one of which was potentially malignant and followed by carcinoma, with secondary nodular hyperplasia of the remaining gland at necropsy due to late chronic renal failure. The mode of presentation in 1945 with vomiting, polydipsia, and polyuria is attributed to hypercalcaemia although there is no record of the serum calcium at that time. The fact that in 1948 there was marked hypercalcaemia and renal failure was improved after parathyroidectomy and so remained for at least six years does not support the second possibility that chronic renal failure occurring at an early stage in this patient's illness was the cause of the hyperparathyroidism but we are unable to indicate with any degree of certainty the precise sequence of events in this case. There is no record of the state of the other parathyroid glands at the time of the initial operation. In favour of the view that there was chief cell hyperplasia with development of two autonomous adenomas is the observation that in relation to the capsule of the right adenoma removed surgically there was some compressed but apparently hyperplastic parathyroid tissue devoid of fat cells. If this is the sequence of events it would obviate the need to explain the presence of secondary hyperplasia due to renal failure in the presence of a functioning parathyroid carcinoma. The secondary hyperplasia would otherwise have had to occur in the absence of its usual stimulus, namely, hypocalcaemia, since low serum calcium values were only observed in the postoperative period for about six months. It has been suggested (Drake, Albright, and Castleman, 1937) that the stimulus to hyperplasia may be hyperphosphataemia but there is considerable evidence that hypocalcaemia is the stimulating factor (Nordin, 1958). In any event, serum phosphorus levels in the present patient were consistently in the low normal range until terminal azotaemia developed. Golden et al (1965) suggested that secondary parathyroid hyperplasia in association with an adenoma might be brought about by a greater need for parathormone when renal failure develops than can be provided by the adenoma. In the present case we would need to suggest that the carcinoma behaved similarly. In view of these difficulties it seems more logical to postulate that hyperplasia was the initial change which progressed to uninodular lesions in two glands and later to carcinoma with nodular hyperplasia persisting in the remaining gland. Although this view has theoretical attractions we cannot exclude the possibility that the changes in the remaining gland were secondary to the terminal chronic renal failure.

Black and Utley (1968) and Black (1969) have emphasized the difficulty involved in the differential diagnosis of primary parathyroid hyperplasia and adenoma and indicate that chief cell hyperplasia frequently masquerades as adenoma. In view of the difficulties in histological interpretation one cannot exclude the possibility that the parathyroid tissue on the outer aspect of the tumour capsule represented infiltration at the time of the operation. The cellular pattern in this tissue, however, suggested otherwise. Thus the cells were uniform in size, the nuclei were smaller than those in the main tumour, and in the carcinoma at necropsy and mitoses were not identified.

Finally it might be useful to indicate some of the features suggesting carcinoma in a case of hyperparathyroidism. The tumour is large enough to be palpated clinically in about $45 \%$ of cases whereas a benign adenoma is palpable in only about $10 \%$ of cases. The serum calcium level is often very high (mean $16.0 \mathrm{mg} / 100 \mathrm{ml}$ ) compared with the levels noted with benign adenomas, and in the present case was $19.3 \mathrm{mg} / 100 \mathrm{ml}$. Bone disease occurs in $70 \%$, pancreatitis in $15 \%$, and renal disease in $30 \%$ of cases of parathyroid carcinoma. At operation the capsule of 'adenomas' which have subsequently behaved in a malignant manner have often been 
thick and about $40 \%$ are adherent to adjacent tissues by what appears to be fibrous inflammatory tissue. If this is cut cells may be disseminated with multiple 'pearl-like' recurrences of tumour in the wound (Cope, 1966).

Several histological features suggest malignancy in an 'adenoma': (1) the presence of a thick capsule with fibrous trabeculae extending into the substance of the 'adenoma' and infiltration of these by tumour cells; (2) prominent cells with enlarged or giant nuclei and multinucleated cells are a feature of benign adenomas and are inconspicuous in carcinoma; (3) carcinomas often show a tendency to a trabecular arrangement with an elongated cylindrical or spindle shape to individual cells which are especially conspicuous surrounding vessel walls; (4) the presence of occasional mitoses is probably unhelpful but it is usually difficult to find mitoses at all in benign adenomas and they are always present in carcinomas (Castleman, 1952).

Treatment of parathyroid carcinoma is almost confined to surgical excision and radiotherapy has usually proved ineffective. Response to chemotherapy using hexestrol has been reported (Goepfert et al, 1966).

We are indebted to our colleagues in the Royal Victoria Infirmary, Newcastle upon Tyne, and in particular to Dr H. A. Dewar and Professor I. Rannie for permission to use their records, and to Professor R. J. Scothorne and Dr J. Bell, Department of Anatomy, University of Newcastle upon Tyne.

\section{References}

Beahrs, O. H., Angelos, S. P., and Woolner, L. B. (1963). Carcinoma of the parathyroid gland: report of a case. Surg. clin. N. Amer., 43, 1123-1127.

Black, B. K. (1954). Carcinoma of the parathyroid. Ann Surg., 139, 355-363.

Black, B. K., and Ackerman, L. V. (1950). Tumors of the parathyroid. A review of 23 cases. Cancer (Philad.), 3, 415-444.

Black, B. M., and Haynes, A. L. (1951). Hyperfunctioning carcinoma of parathyroid origin with local recurrence and metastases. Proc. Mayo Clin., 26, 309-312.

Black, W. C., III (1969). Correlative light and electron microscopy in primary hyperparathyroidism. Arch. Path., 88, 225-241.

Black, W. C., III, and Utley, J. R. (1968). The differential diagnosis of parathyroid adenoma and chief cell hyperplasia. Amer.J. clin. Path., 49, 761-775.

Caley, J. P., Jones, E. E., and Collins, D. H. (1962). Fat al recurrence of parathyroid carcinoma after seven years. J. clin. Path., 15, 438-445.

Castleman, B. (1952). Tumors of the Parathyroid Glands, Atlas of Tumor Pathology. Fasc. 15. Armed Forces Institute of Pathology, Washington D.C.

Cook, P. B. (1958). Hyperparathyroidism due to parathyroid carcinoma. J. Bone Jt Surg., 40B, 546-551.

Cope,O. (1966). Thestory of hyperparathyroidism at the Massachuset ts General Hospital. New Engl. J. Med., 274, 1174-1182.

Cope, O., Keynes, W. M., Roth, S. I., and Castleman, B. (1958). Primary chief-cell hyperplasia of the parathyroid glands: a new entity in the surgery of hyperparathyroidism. Ann. Surg., 148, 375-388.

Davies, D. R., Dent, C. E., and Watson, L. (1968). Tertiary hyperparathyroidism. Brit. med. J., 3, 395-399.

De Wesselow, O. L. V., and De Wardener, H. E. (1949). Carcinoma of the parathyroid gland with hyperparathyroidism. Lancet, 1, 820-823.

Drake, T. G., Albright, F., and Castleman, B. (1937). Parathyroid hyperplasia in rabbits produced by parenteral phosphate administration. J. clin. Invest., 16, 203-206.

Ellis, J. T., and Barr, D. P. (1951). Metastasizing carcinoma of the parathyroid gland with osteitis fibrosa cystica and extensive $\mathcal{C}$ calcinosis. Amer. J. Path., 27, 383-406.

Fredell, C. H., McIver, M. A., and Ferrebee, J. W. (1957). Carcinoma of a parathyroid gland with hyperparathyroidism: report of a case. Surgery, 42, 959-965.

Gentile, R. J., Skinner, H. L., and Ashburn, L. L. (1941). The parathyroid glands: malignant tumor with osteitis fibrosa cystica. $\vec{\Omega}$ Surgery, 10, 793-810.

Goepfert, H., Smart, C. R., and Rochlin, D. B. (1966). Metastatic N parathyroid carcinoma and hormonal chemotherapy: case $\rightarrow$ report and response to hexestrol. Ann. Surg., 164, 917-920.

Golden, A., Canary, J. J., and Kerwin, D. M. (1965). Concurrence of i hyperplasia and neoplasia of the parathyroid glands. Amer. J. Med., 38, 562-578.

Haff, R. C., Black, W. C., and Ballinger, W. F., II (1970). Primary hyperparathyroidism: changing clinical, surgical and pathologic aspects. Ann. Surg., 171, 85-92.

Heptinstall, R. H. (1966). Pathology of the Kidney, p. 739. Churchill, London.

Holmes, E. C., Morton, D. L., and Ketcham, A. S. (1969). Parathyroid carcinoma: a collective review. Ann. Surg., 169, 631-640.

Kelly, T. R. (1969). Parathyroid carcinoma: a case report and review of the literature. Amer. Surg., 35, 374-376.

King, E. S. J., and Wood, B. (1950). Parathyroid tumour with visceral met astases. J. Path. Bact., 62, 29-35.

Kramer, W. M. (1970). Association of parathyroid hyperplasia with neoplasia. Amer. J. clin. Path., 53, 275-283.

Lazar, A. W., Landau, R. L., and Kappas, A. (1961). Metastatic carcinoma of parathyroid and persistent hyperparathyroidism. Arch. Path., 72, 484-489.

Mansour, K. A., and Letton, A. H. (1967). Adenocarcinoma of the parathyroid gland: review of the literature and report of one case. Amer. Surg., 33, 378-381.

Meyer, K. A., and Ragins, A. B. (1943). Carcinoma of the parathyroid gland. Surgery, 14, 282-295.

Newton, N. C., and Sumich, M. G. (1968). Hyperfunctioning parathyroid carcinoma. Med. J. Aust., 2, 219-222.

Nordin, B. E. C. (1958). Primary and secondary hyperparathyroidism. Advanc. intern. Med., 9, 81-105.

Norris, E. H. (1948). Carcinoma of the parathyroid glands with a preliminary report of 3 cases. Int. Abstr. Surg., 86, 1-21.

Pollack, S., Goldin, R. R., and Cohen, M. (1961). Parathyroid carcinoma. A report of two cases and a review of the literature. Arch. intern. Med., 108, 583-587.

Rapoport, A., Sepp, A. H., and Brown, W. H. (1960). Carcinoma of the parathyroid gland with pulmonary metastases and cardiac death. Amer. J. Med., 28, 443-452.

Scharf, Y.,Better, O., Gellei, B., Hemli, J., Peled, B., and Brandstaetter, S. (1969). Long-standing recurrent pancreatitis as manifested in parathyroid carcinoma. Amer. J. Gastroent., 52, 111-115.

Smith, J. F. (1970). Parathyroid adenomas associated with the malabsorption syndrome and chronic renal disease. J. clin. Path., N 23, 362-369.

Stephenson, H. U., Jr. (1950). Malignant tumours of the parathyroid $\mathrm{N}$ glands: a review of the literature with report of a case. Arch. Surg., 60, 247-266.

Straus, F. H., II, a nd Paloyan, E. (1969). The pathology of hyperparathyroidism. Surg. clin. N. Amer., 49, 27-42.

Tange, J. D. (1958). Carcinoma of the parathyroid. Brit. J. Surg., 46, 254-259.

Woolner, L. B., Keating, F. R. Jr., and Black, B. M. (1952). Tumors $\mathscr{D}$ and hyperplasia of parathyroid glands: a review of the pathological findings in 140 cases of primary hyperparathyroidism. Cancer (Philad.), 5, 1069-1088.

Wray, S. (1953). Carcinoma of the parathyroid gland. J. Path. Bact., 66, 231-234.

Young, J. H., and Emerson, K., Jr. (1949). Parathyroid carcinoma associated with acute parathyroid intoxication. Ann. intern. Med., 30, 823-837. 